\title{
Prevalence Rate and Clinical Features of Fissure-in-Ano in a Private Surgical Clinic in Al-Diwaniyah Province, Iraq
}

\author{
Muhammad Kerim Jasim Albo Jumaa ${ }^{1}$, Abdulameer Abdulhussein Kadhim ${ }^{2}$, Ali Hameed Atash Al Badri ${ }^{3}$ \\ ${ }^{\text {I} D r ., ~ M . B . C h . B ., ~ H i g h ~ D i p l o m a ~ i n ~ G e n e r a l ~ S u r g e r y ~(K u f a ~ U n i v e r s i t y ~ 2008) / G e n e r a l ~ S u r g e o n / A l-D i w a n i y a h ~}$ \\ Burn Specialized Center/Al-Diwaniyah Province, Iraq, ${ }^{2}$ Dr., M.B.Ch.B., High diploma in general surgery (Kufa \\ University 2008)/General surgeon/Al-Diwaniyah Teaching Hospital/Departmrnt of General Surgery/Al-Diwaniyah/ \\ Iraq, ${ }^{3}$ Dr., M.B.Ch.B., High Diploma Degree in General Surgery (Kufa-University 2008)/General Surgeon/Al- \\ Hamza General Hospital/Department of General Surgery/Al-Diwaniyah/Iraq
}

\begin{abstract}
Background: One of the most frequent causes of anal discomfort and pain is fissure in ano in which there is a linear tear in the squamous epithelium that lines the anal canal at location distal to dentate line. The disease is encountered in both male and female gender and no age is immune particularly middle age and young age. Little is known about the prevalence rate and clinical presentation in our community of Al-Diwaniyah Province, Iraq.
\end{abstract}

Aim of the Study: The current study was aiming at identifying the prevalence and clinical Presentation of Fissure-in-Ano in a Private Surgical Clinic in Al-Diwaniyah Province, Iraq.

Patients and Method: The current cross sectional study was carried out at a private surgical clinic in AlDiwaniyah Province, Iraq. The study duration extended from January the $2^{\text {nd }} 2019$ to December the $31^{\text {st }}$ 2019.During this period patients with an age between 20-60 years were enrolled based on their clinical presentation of an anorectal problem. Any patient with previous anal surgery, with malignant disorder, pregnancy or lactation was excluded from the study. All enrolled patients were examined by digital rectal examination and proctoscopic examination. Sigmoidoscopy and colonoscopy were done as required.

Result: The study included a total of 314 patients with anorectal complaint of whom 78 patients had fissure in ano making the prevalence rate as $24.8 \%$. Those patients with anal fissure were categorized into 57 (73.1\%) males and 21 (26.9\%) females. Most patients were between 31-40 years of age and the mean age of all patients was 34.98 \pm 7.81 years and the range was 20-60 years. Most of fissures were located in the posterior midline location and the minority of them was seen in an anterior midline location. The majority of patients had acute disease and the minority of them had chronic disease with some having sentinel pile.

Conclusion: It has been shown therefore, that anal fissure is a common problem in our community and that young age and middle age men are the target of majority of cases. The clinical features vary according to age and gender

Keywords: Fissure-in-Ano, Al-Diwaniyah Province, Iraq.

\section{Introduction}

One of the most frequent causes of anal discomfort and pain is fissure in ano in which there is a linear tear in the squamous epithelium that lines the anal canal at location distal to dentate line ${ }^{1,2}$. The disease is encountered in both male and female gender and no age is immune particularly middle age and young age
(3-5). The usual site of occurrence is the posterior or the anterior midline, and it extends from the dentate line toward the anal verge ${ }^{2,6,7}$. The pathogenesis and exact etiology of the disease are not well recognizes; however, the increase in the local tone of internal anal sphincter and the presence of local ischemia have been reported to be associated with increased incidence of the disease $e^{2,6,8,9}$. Constipation and passage of hard stool has been proposed 
as an important initial event in the pathology of anal fissure ${ }^{2,8}$. Anal fissure acquisition has been also linked to low fiber diet 1,2,8,10,11. Other associated factors have been previously reported such as childbirth in women, spicy food and poor anal cleaning ${ }^{11-14}$.

The disease is associated with poor quality of life because of severe pain that may lead to delay of defecation and exacerbation of pathology due to chronic constipation, in addition to bleeding per-rectum and spasm of anal sphincter ${ }^{15-17}$.

There has been a tradition to classify the disease into acute and chronic typed based on duration from onset of symptoms. Those who present within 3 to 4 weeks of onset are categorized as having acute disease with self-limiting course and well response to conservative measures such as stool softeners and high fiber $\operatorname{diet}^{1,18}$. The other type is the chronic one, in which the clinical features are present for more than 6 weeks and it usually fails to heal spontaneously or to respond to conventional treatment and surgical intervention is often required 6,19 . It is suggested that spasm of internal sphincter with associated ischemia is the most common cause for persistence and chronicity of anal fissure 2,6,8,9. Another suggested classification is based on etiology into idiopathic one with no obvious cause and secondary one in which there is some predisposing pathology such as malignant neoplasm, tuberculosis and inflammatory bowel disease ${ }^{1,20}$.

The current study was aiming at identifying the prevalence and clinical Presentation of Fissure-in-Ano in a Private Surgical Clinic in Al-Diwaniyah Province, Iraq.

\section{Patients and Method}

The current cross sectional study was carried out at a private surgical clinic in Al-Diwaniyah Province, Iraq. The study duration extended from January the $2^{\text {nd }} 2019$ to December the $31^{\text {st }} 2019$. During this period patients with an age between 20-60 years were enrolled based on their clinical presentation of an anorectal problem. Any patient with previous anal surgery, with malignant disorder, pregnancy or lactation was excluded from the study. All enrolled patients were examined by digital rectal examination and proctoscopic examination. Sigmoidoscopy and colonoscopy were done as required.

The study was approved based on ethical approval issued by ethical approval committee of the directorate of health in the province and college of medicine and a verbal consent was obtained from every participant.

Data were collected and transformed into a spread sheet of an SPSS (statistical package for social sciences) software (Chicago, IBM, USA, version 23.0) for purpose of statistical description and analysis.

\section{Results}

The study included a total of 314 patients with anorectal complaint of whom 78 patients had fissure in ano making the prevalence rate as $24.8 \%$ (Figure 1). Those patients with anal fissure were categorized into 57 $(73.1 \%)$ males and $21(26.9 \%)$ females (Table 1). Most patients were between 31-40 years of age and the mean age of all patients was $34.98 \pm 7.81$ years and the range was 20-60 years (table 1).

The most common clinical features were pain during defecation, constipation, bleeding per rectum, pruritus and discharge (table 2). Both pain during defecation and constipation were common in men, whereas, women were complaining of bleeding per-rectum, pruritus and discharge (table 2). According to age, young patients (20-30 years) were complaining mostly of bleeding perrectum, middle age patients (31-40) were complaining mostly of pain and constipation and old patients were complaining predominantly of pruritus and discharge (table 3). Most of fissures were located in the posterior midline location and the minority of them was seen in an anterior midline location. The majority of patients had acute disease and the minority of them had chronic disease with some having sentinel pile. 
Others

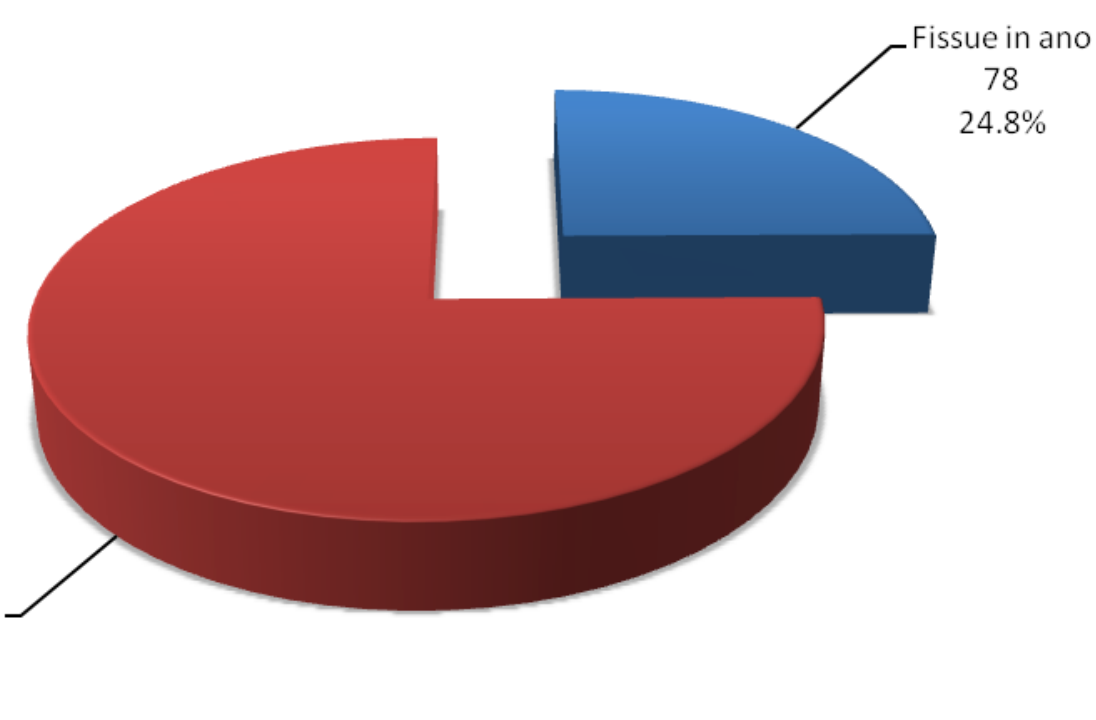

Figure 1: Pie chart showing the prevalence rate of fissure in ano out of all cases with anorectal conditions

Table 1: Frequency distribution of patients according to age and gender

\begin{tabular}{|c|c|c|c|c|c|}
\hline \multirow{2}{*}{ Age (Years) } & \multirow{2}{*}{ Total $n(\%)$} & \multicolumn{2}{|c|}{ Male } & \multicolumn{2}{|c|}{ Female } \\
\hline & & $\mathrm{n}$ & $\%$ & $\mathrm{n}$ & $\%$ \\
\hline $20-30$ & $10(12.8 \%)$ & 7 & 70.0 & 3 & 30.0 \\
\hline $31-40$ & $41(52.6 \%)$ & 31 & 75.6 & 10 & 24.4 \\
\hline $41-50$ & $21(26.9 \%)$ & 15 & 71.4 & 6 & 28.6 \\
\hline $51-60$ & $6(7.7 \%)$ & 4 & 66.7 & 2 & 33.3 \\
\hline Total & $78(100.0 \%)$ & 57 & 73.1 & 21 & 26.9 \\
\hline Mean age \pm SD & $34.98 \pm 7.81$ & \multicolumn{2}{|c|}{$34.91 \pm 8.07$} & \multicolumn{2}{|c|}{$35.19 \pm 6.84$} \\
\hline Range & $20-60$ & \multicolumn{2}{|c|}{$20-57$} & \multicolumn{2}{|c|}{$21-60$} \\
\hline
\end{tabular}

SD: standard deviation

Table 2: Clinical features in association with anal fissure according to gender

\begin{tabular}{|l|c|c|c|}
\hline Symptom & Total $\boldsymbol{n}(\mathbf{\%})$ & Male $\boldsymbol{n}(\mathbf{\%})$ & Female $\boldsymbol{n}(\mathbf{\%})$ \\
\hline Pain during defection & $63(80.8 \%)$ & $49(86.0 \%)$ & $14(66.7 \%)$ \\
\hline Constipation & $48(61.5 \%)$ & $37(64.9 \%)$ & $11(52.4 \%)$ \\
\hline Bleeding per rectum & $24(30.8 \%)$ & $15(26.3 \%)$ & $9(42.9 \%)$ \\
\hline Pruritus & $9(11.5 \%)$ & $3(5.3 \%)$ & $6(28.6 \%)$ \\
\hline Discharge & $6(7.7 \%)$ & $3(5.3 \%)$ & $3(14.3 \%)$ \\
\hline
\end{tabular}

Table 3: Clinical features in association with anal fissure according to age

\begin{tabular}{|l|c|c|c|c|}
\hline \multirow{2}{*}{ Symptom } & \multicolumn{4}{|c|}{ Age (Years) } \\
\cline { 2 - 5 } & $\mathbf{2 0 - 3 0}$ & $\mathbf{3 1 - 4 0}$ & $\mathbf{4 1 - 5 0}$ & $\mathbf{5 1 - 6 0}$ \\
\hline Pain during defection & 6 & 37 & 17 & 3 \\
\hline Constipation & 5 & 27 & 14 & 7 \\
\hline Bleeding per rectum & 7 & 2 & 4 & 2 \\
\hline Pruritus & 1 & 1 & 3 & 2 \\
\hline Discharge & 0 & & & 2 \\
\hline
\end{tabular}




\section{Discussion}

The prevalence rate of fissure in ano in this study was $24.8 \%$ out of all anorectal conditions. This figure is somewhat less than that reported by a previous Indian report of $30.7 \%{ }^{21}$. It has been shown that the disease is far more common in men than in women and this finding is consistent with previous reports ${ }^{21}$. Indeed, the high prevalence rate of disease in men in the current study may not reflect the true status of the disease and may be based on some cultural aspects in that men often seek medical advice for such conditions, whereas, females are hesitant in seeking medical advice for anorectal conditions because in our culture it is a usual tradition that women avoid being examined by a male doctor when having medical troubles in such embarrassing location ${ }^{22}$.

In the current study, the main clinical features were pain during defecation, constipation and bleeding perrectum (in that order); whereas, in previous reports bleeding was more common than constipation, but, the symptom of pain was also predominant ${ }^{21}$. Our study has shown that men have symptoms that are different from that of women in term of frequency, pain and constipation being highly frequent in men, whereas, bleeding and pruritus being more frequent in women, in accordance with previous reports ${ }^{21}$.

The most common age group affected in our study were patients with an age range of 31-40 (middle age), in accordance with previous observation ${ }^{21}$. There was also substantial variation in clinical presentation with respect to age in the current study in such a way that young patients mainly had bleeding, middle age group mainly had pain and older age group mainly had pruritus and discharge. In previous reports, young patients have been shown to complain of pain and bleeding ${ }^{21}$. Regarding the location of anal fissure, it has been shown that posterior midline site is by far the most prevalent and this is in consistence with previous reports ${ }^{21}$.

\section{Conclusion}

It has been shown therefore, that anal fissure is a common problem in our community and that young age and middle age men are the target of majority of cases. The clinical features vary according to age and gender.

Acknowledgement: Deep thanks are to be expressed to all patients participated in this study for their kind acceptance to be enrolled and their generous cooperation.

Financial Disclosure: There is no financial disclosure.

Conflict of Interest: None to declare.

Ethical Clearance: All experimental protocols were approved under the Al-Diwaniyah Burn Specialized Centerand all experiments were carried out in accordance with approved guidelines.

\section{References}

1. Schlichtemeier S, Engel A. Anal fissure. AustPrescr. 2016;39(1):14-17.

2. Beaty JS, Shashidharan M. Anal Fissure. Clin Colon Rectal Surg. 2016;29(1):30-37.

3. Mapel DW, Schum M, Von Worley A. The epidemiology and treatment of anal fissures in a population-based cohort. BMC Gastroenterol. 2014;14:129.

4. Foxx-Orenstein AE, Umar SB, Crowell MD. Common anorectal disorders. GastroenterolHepatol (N Y). 2014;10(5):294-301.

5. Salih AM. Chronic anal fissures: Open lateral internal sphincterotomy result; a case series study. Ann Med Surg (Lond). 2017;15:56-58.

6. Zaghiyan KN, Fleshner P. Anal fissure. Clin Colon Rectal Surg. 2011;24(1):22-30.

7. Rakinic J. Anal fissure. Clin Colon Rectal Surg. 2007;20(2):133-137.

8. Villalba H, Villalba S, Abbas MA. Anal fissure: a common cause of anal pain. Perm J. 2007;11(4):6265.

9. Yu SW, Rao SS. Anorectal physiology and pathophysiology in the elderly. ClinGeriatr Med. 2014;30(1):95-106.

10. Ho KS, Tan CY, MohdDaud MA, Seow-Choen F. Stopping or reducing dietary fiber intake reduces constipation and its associated symptoms. World J Gastroenterol. 2012;18(33):4593-4596.

11. Gupta PJ. Treatment of fissure in ano- revisited. Afr Health Sci. 2004;4(1):58-62.

12. Poskus $\mathrm{T}$, Buzinskienè $\mathrm{D}$, Drasutiene $\mathrm{G}$, Samalavicius NE, Barkus A, Barisauskiene A, Tutkuviene J, Sakalauskaite I, Drasutis J, Jasulaitis A, Jakaitiene A. Haemorrhoids and anal fissures during pregnancy and after childbirth: a prospective cohort study. BJOG. 2014;121(13):1666-71. 
13. Gupta PJ. Consumption of red-hot chili pepper increases symptoms in patients with acute anal fissures. A prospective, randomized, placebocontrolled, double blind, crossover trial. ArqGastroenterol. 2008;45(2):124-7.

14. Şişik A, Başak F, Hasbahçeci M, et al. Recovery from hemorrhoids and anal fissure without surgery. Turk J Gastroenterol. 2020;31(4):289-294.

15. Griffin N, Acheson AG, Tung P, Sheard C, Glazebrook C, Scholefield JH. Quality of life in patients with chronic anal fissure. Colorectal Dis. 2004;6(1):39-44.

16. Tsunoda A, Kashiwagura Y, Hirose K, Sasaki T, Kano N. Quality of life in patients with chronic anal fissure after topical treatment with diltiazem. World J Gastrointest Surg. 2012;4(11):251-255.

17. Owen HA, Buchanan GN, Schizas A, Cohen R, Williams AB. Quality of life with anal fistula. Ann R CollSurg Engl. 2016;98(5):334-338.
18. Nelson RL. Anal fissure (chronic). BMJ ClinEvid. 2014;2014:0407.

19. Latif A, Ansar A, Butt MQ. Morbidity associated with treatment of chronic anal fissure. Pak J Med Sci. 2013;29(5):1230-1235.

20. Madalinski MH. Identifying the best therapy for chronic anal fissure. World J GastrointestPharmacolTher. 2011;2(2):9-16.

21. Varadarajan MS, Sony PS, Anandan H. Prevalence and Clinical Presentation of Fissure-in-ANO in A Tertiary Care Centre. International Journal of Scientific Study. 2018; 5 (12): 70-72.

22. Khan RM, Itrat M, Ansari AH, Ahmer SM, Zulkifle. Prevalence of Fissure-in-Ano among the Patients of Anorectal Complaints Visiting Nium Hospital. J Community Med Health Educ2015; 5:344. 